\title{
AOR
}

Selected Papers of \#AolR2019:

The $20^{\text {th }}$ Annual Conference of the Association of Internet Researchers Brisbane, Australia / 2-5 October 2019

\section{LASTING IMPACTS OF 1990S INTERNET GOVERNANCE}

\author{
Meghan Grosse \\ Washington College
}

\section{Introduction}

Over the past few years, Facebook has found itself mired in out controversy after the next. During the 2016 U.S. presidential election, the company received criticism when it was revealed that Russian groups had created fraudulent social media accounts on their site in order to interfere with the elections - creating anti-Hillary groups, groups stoking fears of minority populations, and materials accusing the Democratic Party of voter fraud in an attempt to discourage voter turn-out.

In April 2018 Facebook's founder and CEO, Mark Zuckerberg, was called before U.S. Congress to testify about this breach of trust, not just by the social media platform, but in the election process upon which the U.S. federal government relies. The question is, how did we get to this point; the point where foreign entities are affecting political outcomes in other countries through a website created by a private American corporation on a media platform wherein the lines between the cultures and legal systems of different countries is sometimes difficult to draw? To consider this question, we have to look back at the foundations of the commercial internet, and for that, I point us back to consider the policies developed by the administration of U.S. President Bill Clinton regarding governance of the global internet. Broadly, this research seeks to address the following question: Whose interests drive the use and development of the early internet, and as new concerns about sovereignty arise, how are questions of internet governance addressed to ensure that the needs of citizens around the world are met?

In 2019, it's easy to take for granted that the internet is a commercial system, but in the mid-1990s, the nature of the increasingly global internet was debated as commercial, governmental, and technical interest groups attempted to influence the policies and structures that would guide this system. I return to this history to contextualize contemporary issues and to consider the various stakeholders that influenced earlier internet governance.

Suggested Citation (APA): Grosse, M. (2019, October 2-5). Lasting Impacts of 1990s Internet Governance. Paper presented at AolR 2019: The 20th Annual Conference of the Association of Internet Researchers. Brisbane, Australia: AolR. Retrieved from http://spir.aoir.org. 


\section{Methods/Critical Frameworks}

I examine the era of 1990s internet history through archival analysis. In particular, I engage with the 'Ira Magaziner Electronic Commerce' papers at the Clinton Presidential Library in Little Rock, Arkansas. In looking at this history, I apply a political economy of communication framework that focuses on issues of power and the imbalances they create, particularly as they're built into the structures of media systems.

In this research, I consider three broad groups that are represented in this archive: the technical community, the experts that understood the mechanical workings of the system who also knew its technical capacities and limitations; commercial interest groups, the companies and for-profit institutions investing in the early internet; and official government actors from the United States and abroad as well as representatives from intergovernmental organizations.

In looking at these key groups, the official and unofficial exchanges between them and the policies written related to these exchanges, l'm arguing that the efforts undertaken by the Clinton Administration - while appearing to encourage feedback from and collaboration between government, private and technical actors - were surface efforts to make it appear as though serious, multistakeholder governance was taking place when in actuality, the United States was primarily engaging with capitalist states, and in particular, ones who were interested in, or at least willing to, follow a U.S.-centric approach to internet governance. The inclusion of multiple stakeholders goes beyond any multilateral or state-to-state policy making to include private interests. Though this discourse frames the attention to commercial interests as inclusive and even democratic, including commercial perspectives undercuts the ability for other governments and any form of non-commercial public interest groups to set policy while advancing corporations' ability to do so.

\section{Findings/Conclusions}

In 1994, the Clinton Administration was very public about the fact that the commercialization of the internet was a top priority for the U.S. Government. One important space where we can consider the overlapping interests of the groups noted above was in the development and control of the Domain Name System or DNS. This system is the backbone of the commercial internet. Connecting IP addresses with easy to remember names and addresses allows users without technical expertise to more easily navigate the internet. Without a system like this, the internet does not become a commercial system like we know it today. Understanding the commercial interest in this system, the Clinton Administration understood the need to control and protect a stable DNS in order to encourage investment by private corporations. Issues of intellectual property and trademark were prioritized, and U.S. interests were disproportionately offered generic top-level domains, such as addresses ending in .com, while interests in other countries were more likely to operate using countries code domains, .uk for the United Kingdom, .au for Australia, .de for Germany and so forth. As a result, U.S. preferences became a kind of default setting for the internet despite the persistence of 
romantic or utopic narratives of the internet that framed the internet as a global system on which everyone had equal access.

The prioritization of commercial interests has continued impacts. In addition to the issues with the U.S. presidential election in 2016, other countries around the world remain concerned about the ways in which Facebook, a private American corporation, could harm their national politics. In February 2019, British Parliament released a report critical of the corporation. Parliament argued that Facebook's influence on their national politics resulted from serious flaws in oversight, flaws that have resulted in Facebook operating as if above the law and in total disregard of its users' privacy interests. In that same month, polls in Canada indicated that a majority of citizens there believed that Facebook would negatively impact their next federal election. This is where we can see those early iterations of multistakeholderism that set roots in the 1990s - with commercial interests taking priority over more democratic concerns.

\section{Connection to Conference Themes}

This paper addresses concerns related to trust in governance - considering how various stakeholders in early internet governance were represented (or not) in the final policy decisions that shaped the structures and coordination of the internet. I argue that the focus on including commercial interests in these earlier discussions has had a lasting impact on the ways in which the internet operates to this day. In considering recent controversies that stem from the blurring lines of online sovereignty, wherein commercial and governmental interests become interwoven without a clear sense of who bears the responsibility when the system operates against the interests of its users, it becomes essential to consider the historical foundations which may have led to this moment. 